DOI: $10.12957 /$ teias.2021.59996

\title{
UMA PROPOSTA METODOLÓGICA DE CONSCIENTIZAÇÃO PARA A PRÁTICA DE EDUCAÇÃO AMBIENTAL ESCOLAR:
}

a partir da Teoria de Paulo Freire

\author{
Silvia Patrícia da Silva Marques \\ Carla Luciane Blum Vestena \\ Leandro Redin Vestena
}

Resumo

O presente trabalho apresenta os resultados de uma proposta metodológica, intitulada "Tríade da Conscientização" para o ensino da Educação Ambiental escolar, a partir da teoria de Paulo Freire. Trata-se de uma pesquisa qualitativa do tipo pesquisa-ação e com utilização da análise do discurso. A pesquisa foi desenvolvida em uma turma de $2^{\circ}$ ano do Ensino Médio, em um colégio público do interior do Paraná. $\mathrm{Na}$ aplicação da proposta metodológica, observou-se e avaliou-se a interação, a produção e as respostas dos educandos às atividades propostas. Os resultados demonstraram que a proposta permitiu a exploração e integralização dos conteúdos de Geografia por meio da prática de Educação Ambiental. Percebeu-se também, que essa proposta despertou o interesse dos educandos em buscar novas informações, extrapolando os conteúdos do livro didático.

Palavras-chave: metodologia de ensino; tecnologias educacionais; meio ambiente.

\section{A METHODOLOGICAL PROPOSAL FOR AWARENESS FOR THE PRACTICE OF SCHOOL ENVIRONMENTAL EDUCATION: from Paulo Freire's theory}

\begin{abstract}
This paper presents the results of a methodological proposal entitled "Awareness Triad" for Environmental Education in schools, based on the theory of Paulo Freire. This was a qualitative action research study which also used discourse analysis. The study was conducted with a class of 11th grade students at a public high school in the interior region of the state of Paraná, Brazil. When applying the methodological proposal, student interaction, production and answers to the proposed activities were observed and assessed. The results demonstrated that the proposal Geography and Environmental Education contents to be explored and integrated. This proposal was also seen to awaken students' interest in seeking new information, beyond the contents of the textbook.
\end{abstract}

Keywords: teaching methodology; education technologies; environment.

\section{UNA PROPUESTA METODOLÓGICA DE CONCIENCIACIÓN PARA LA PRÁCTICA DE LA EDUCACIÓN AMBIENTAL ESCOLAR:} de la teoría de Paulo Freire

Resumen

El presente trabajo presenta los resultados de una propuesta metodológica, titulada "Tríada de Conciencia" para la enseñanza de la Educación Ambiental escolar, basada en la teoría de Paulo Freire. Es una investigación cualitativa del tipo de investigación de acción y con el uso del análisis del discurso. La investigación se desarrolló en una clase de segundo año de secundaria, en una escuela pública en el interior 
de Paraná. En la aplicación de la propuesta metodológica, se observó y evaluó la interacción, producción y respuestas de los estudiantes a las actividades propuestas. Los resultados mostraron que la propuesta permitió la exploración e integración de los contenidos de Geografía a Educación Ambiental. También se notó que esta propuesta despertó el interés de los estudiantes en buscar nueva información, extrapolando el contenido del libro de texto.

Palabras clave: metodología de enseñanza; tecnologías educativas; medio ambiente.

\section{INTRODUÇÃO}

A Educação Ambiental brasileira nasceu como consequência de ações externas por um mundo sustentável, ações estas que tiveram início pós II Guerra Mundial, e estenderam-se por toda segunda metade do século XX, sendo fruto de movimentos externos. No Brasil, a Educação Ambiental foi institucionalizada em 1999 pela lei 9.795/1999 (BRASIL, 1999), essa estabelece a Política Nacional de Educação Ambiental, porém ela não altera a redação da Lei de Diretrizes e Bases da Educação brasileira (LDB), apenas agrega-lhe complementações (BRASIL, 2013). Embora, a Educação ambiental deva estar "relacionada com a prática das tomadas de decisões e a ética que conduzem para a melhoria da qualidade de vida" (SATO, 2002, p. 23-24), sem deixar de contemplar as questões éticas e políticas (BRÜGGER, 1999). No entanto, ainda não houve uma implementação efetiva da mesma junto às instituições de ensino básico, ficando relegada a projetos esporádicos no decorrer do ano letivo (BRASIL, 1996; CZAPSKI, 1998; VESTENA, 2011; GOMES et al., 2017).

Uma metodologia de Educação Ambiental para o Ensino de Geografia pautada por três eixos: a Educação Ambiental, o Ensino de Geografia e o uso dos recursos didáticos tecnológicos foi proposta com o objetivo de construir "valores sociais, conhecimentos, habilidades, atitudes e competências voltadas para a conservação do meio ambiente, bem como de uso comum do povo, essencial à sadia qualidade de vida e sua sustentabilidade" (BRASIL, 1999, s/p), denominada Tríade da Conscientização.

A metodologia Tríade da Conscientização parte do princípio que o ser humano, por suas ações, já ultrapassou o limite suportável de exploração e intervenção no meio ambiente (GUIMARÃES, 1995) e que a Educação Ambiental nasce com a função de mudar este paradigma (LEFF, 1999). Trata-se de um caminho para um presente e um futuro de justiça ambiental, enquanto que o Ensino de Geografia pode, conforme Sansolo e Cavalheiro (2003), contribuir com a Educação ambiental por meio da politização da sociedade.

A Tríade trabalha com a perspectiva Freiriana de que não existe saber completo, somos seres inacabados. A sociedade e o mundo que nos cerca está em construção, vendo "o presente como um tempo de possibilidades e não de determinismos" (FREIRE, 1996, p.59). Assim, entende-se que educador e educando são sujeitos da história e não expectadores. Logo, [...] "nas condições de verdadeira aprendizagem os educandos vão se transformando em reais sujeitos da construção e reconstrução do saber ensinado, ao lado do educador, igualmente sujeito do processo" (FREIRE, 1996, p. 26).

Nesta perspectiva, a educação é uma forma de intervenção no mundo (FREIRE, 1996). Logo, para se repensar a educação é necessário saber que mundo necessitamos ao levar em consideração a sociedade imediatista, hedonista, conectada e consumista de hoje, cujas relações entre ser humano e meio ambiente são de injustiça. Percebe-se ser necessário uma educação que 
busque estabelecer relações mais justas, por meio da sensibilização e da conscientização do educando e, por consequência, da sociedade.

A metodologia Tríade da Conscientização emerge frente às inquietações, diante de uma escola pública que anseia por influenciar positivamente o espaço em que se insere, que carece de novos rumos e tem potencial para formar cidadãos conscientes de seus direitos e deveres numa sociedade que exclui, degrada, segrega e ignora.

O conhecimento empírico, adquirido pelas experiências na educação pública, apontava para dificuldades, necessidades e potencialidades do ensino básico público. Tais ideias foram amadurecidas e lapidadas nos últimos dois anos por pesquisas teóricas nas áreas do Ensino de Geografia, Educação, Educação Ambiental e Tecnologias na Educação (MARQUES e VESTENA, 2016), dando corpo à ideia inicial de uma metodologia voltada para a sensibilização dos educandos (VESTENA e VESTENA, 2017).

Tal proposta, denominada de "Tríade da Sensibilização", foi aprimorada no decorrer dos estudos por nós realizados e pelas experiências, sendo sintetizada na metodologia "Tríade da Conscientização". Essa troca de nomenclatura é resultante da adoção da base teóricometodológica Freiriana - a qual compreende que a educação é o caminho para a justiça social e, por consequência, justiça ambiental. Neste sentido, na Tríade da Conscientização, mais que a sensibilização, busca-se a conscientização do indivíduo em prol de um mundo de justiça e sustentabilidade, por meio da educação. A conscientização é um conceito estruturante da prática da educação libertadora, ora "é um processo de criticização das relações consciência-mundo, é condição de assunção do comprometimento humano, diante do contexto histórico social" (FREITAS, 2001, p. 25).

Esta metodologia ainda tem por princípio respeitar os saberes do educando e, para tanto, a prática pedagógica buscou se basear na reflexão-ação de Freire (1994), ou seja, "o saber que realimenta criticamente o fazer, cujo resultado incide novamente sobre o saber e, assim, ambos se refazem continuamente" (KRONBAUER, 2008, p. 27).

Este artigo tem por objetivo apresentar os resultados provenientes da vivência prática realizada a partir da Tríade da Conscientização em um colégio da rede pública de ensino, observando e avaliando a interação, produção e as respostas dos educandos, a partir do legado de Paulo Freire.

\section{TECENDO A TRAJETÓRIA DA PESQUISA}

Trata-se de uma pesquisa qualitativa do tipo pesquisa-ação com utilização da análise do discurso, onde a linguagem foi analisada enquanto forma material da ideologia do sujeito da pesquisa.

Os participantes da pesquisa foram 35 educandos residentes na área rural e urbana do município do Pinhão/PR de diferentes classes sociais, gênero e com idade entre 15 e 17 anos e vínculo educador-educando, "no contexto histórico específico considerando o processo de conscientização do homem e o conhecimento como transformação de si próprio e do mundo" (SATO, 1994, p. 56).

A pesquisa ocorreu no Colégio Estadual Professor Mário Evaldo Morski do município de Pinhão/Paraná, durante o ano de 2016, em aulas Geografia, com duração de 50 minutos, totalizando 20 aulas. 
A metodologia da Tríade da Conscientização fundamenta-se na concepção teórica proposta por Paulo Freire (FREIRE, 1977; FREIRE, 1994; FREIRE, 1996; FREIRE e GUIMARÃES, 2003).

\section{A “Tríade da Conscientização" na teoria}

A Tríade da Conscientização é constituída pela articulação da Educação Ambiental, o Ensino de Geografia e o uso dos recursos didáticos tecnológicos (Figura 1), assim como de componentes emergentes da própria vivência de cada grupo participante. $\mathrm{Na}$ ação-reflexão compreendemos os conhecimentos articulados e se alimentando mutuamente, devido as vivências e trocas estabelecidas em sala de aula e pelo diálogo. Uma vez que, partimos da concepção que o 'conhecimento é inacabado' e "ensinar não é transferir conhecimento, mas criar as possibilidades para a sua própria construção" (FREIRE, 1996).

Figura 1: Componentes articuladores da Tríade da Conscientização

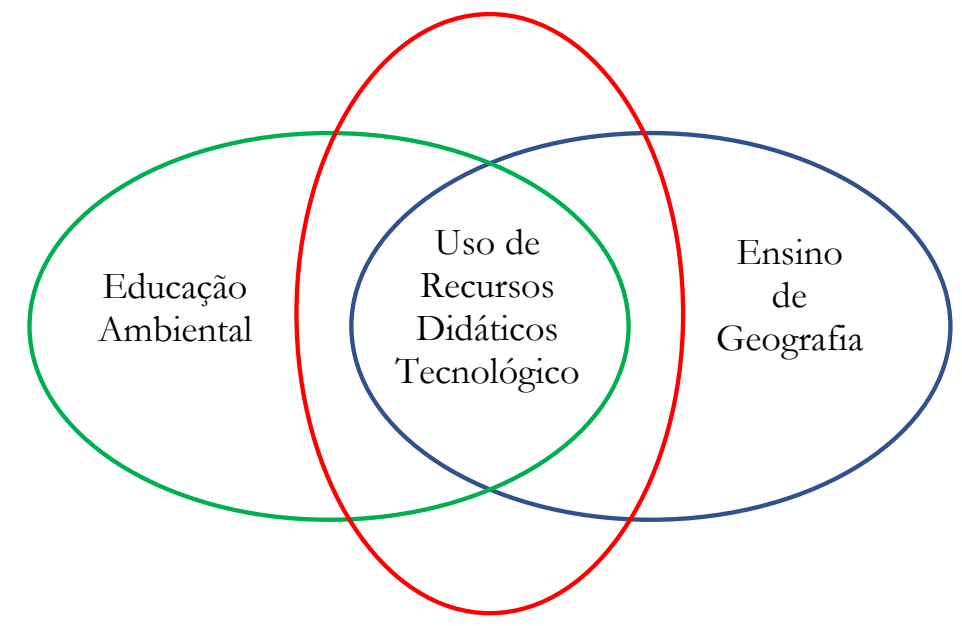

Fonte: Elaborada pelos autores.

O uso das redes sociais intermediou a relação entre o Ensino de Geografia e a Educação Ambiental, bem como efetivou a Educação Ambiental contínua numa perspectiva geográfica em que proporcionou uma ampliação da relação educador-educando e educando-educando tornando-a mais produtiva e prazerosa. Visto que o educador deve ser o problematizador, "ele faz do objeto do conhecimento uma mediação da relação educador-educando e da apreensãoconquista dele, um caminho da libertação, de conscientização da humanização" (FREIRE, 1985). O educador nesta perspectiva teórica, assumi um 'papel diretivo' (FREIRE e SHOR, 1987, p. 187) e de não neutralidade (FREIRE, 1985), pois o educador é político, dirigente e organizador, no sentido Gramsciano (FREIRE, 1986), uma vez que, o homem é produto de circunstâncias diferentes e de educação modificada (MARX e ENGELS, 1984, p. 108).

Percurso metodológico da "Tríade da Conscientização" 
A escolha e a definição de Temas Geradores e do conteúdo programático precisa estar alicerçada, desde sua origem, em uma metodologia coerente com o objetivo da Educação Libertadora para que se promova a conscientização (FREIRE, 1993).

$\mathrm{Na}$ proposta de elaboração das atividades, partiu-se do diálogo com os educandos a respeito dos conteúdos e problematizações locais vivenciadas pelos mesmos, devido a importância da adoção de uma postura dialógica e da prática da dialogicidade para uma educação humanizadora.

As etapas de execução da prática da Tríade da Conscientização podem ser identificadas na Tabela 1, que segue.

\section{Tabela 1: Etapas da prática da Tríade da Conscientização}

\begin{tabular}{cl}
\hline PASSOS & PROCEDIMENTOS \\
\hline $1^{\circ}$ & Levantamento dos recursos didáticos tecnológicos disponíveis no colégio para a aplicação da proposta. \\
\hline $2^{\circ}$ & $\begin{array}{l}\text { Escolha dos conteúdos: a escolha dos conteúdos trabalhados foi estabelecida a partir do Plano de Trabalho Docente (PTD) } \\
\text { que é fundamentado nas Diretrizes Curriculares de Ensino (DCE's) da disciplina de Geografia e no livro didático adotado pela } \\
\text { escola. }\end{array}$ \\
\hline $3^{\circ}$ & $\begin{array}{l}\text { A partir dos conteúdos foram realizados círculos de diálogo com os educandos, a fim de problematizar questões advindas das } \\
\text { realizadas vivenciadas por eles. }\end{array}$ \\
\hline $4^{\circ}$ & $\begin{array}{l}\text { Elaboração do plano de trabalho da “Tríade" junto à turma: a) cronograma de vivências - um documento que contemplou os } \\
\text { conteúdos do primeiro bimestre, os recursos didáticos tecnológicos a serem empregados e as atividades a serem desenvolvidas } \\
\text { em sala de aula, bem como as intervenções da Educação Ambiental em cada aula, e b) recursos utilizados: mapas, imagens, } \\
\text { vídeos, notícias e charges. }\end{array}$ \\
\hline $5^{\circ}$ & $\begin{array}{l}\text { Criação de um grupo no facebook e outro no whatsapp. } \\
\text { Realização de postagens com materiais (vídeos, charges e esquemas) referentes às discussões em sala de aula pelo educador e } \\
6^{\circ}\end{array}$ \\
\hline $7^{\circ}$ & $\begin{array}{l}\text { Registro das vivências em um diário (os nomes dos participantes são fictícios, visando atender o acordado no item } 5 \text { do Termo } \\
\text { de Consentimento Livre e Esclarecido (TCLE) e garantir a confidencialidade). }\end{array}$ \\
\hline $8^{\circ}$ & Registro em imagens da vivência, por meio de fotografias e de instantâneos* da movimentação dos grupos nas redes sociais. \\
\hline $9^{\circ}$ & $\begin{array}{l}\text { Avaliação da metodologia por meio da participação dos educandos (questionamentos, contribuições, exemplos) em sala de } \\
\text { aula e da participação dos educandos nas redes sociais (facebook e whats app), por meio de postagens, comentários, visualizações, } \\
\text { compartilhamentos e curtidas nos posts, utilizando-se da análise do discurso. }\end{array}$ \\
\hline $10^{\circ}$ & $\begin{array}{l}\text { Disponibilização de atividades alternativas à educandos que não postaram comentários nas redes sociais devido à dificuldade } \\
\text { de acesso e/ou até mesmo timidez. }\end{array}$ \\
\hline
\end{tabular}

Fonte: Marques (2016).

Notas: *Também conhecido como captura de tela ou "print screen". É uma espécie de fotografia da tela do computador, smartphone ou tablet, armazenando o que está exposto na tela do aparelho naquele momento.

Os conteúdos, encaminhamento metodológicos da Tríade da Conscientização, bem como as produções dos educandos podem ser visualizadas na Tabela 2.

Tabela 2: Conteúdos, encaminhamentos metodológicos e produções dos educandos

Conteúdos

A organização do
espaço brasileiro:
Constituição do
território e
regionalização

O espaço brasileiro (uma periodização do espaço geográfico)
Encaminhamento metodológico

Produções

- Localização do território brasileiro e reconhecimento do seu limite geográfico e extensão territorial, a partir do uso do Google Earth.

- Observação de slides e reflexão sobre questões ambientais, diversidade, modo de uso e ocupação do solo, bem como as transformações provenientes da mudança da capital brasileira para a região centro-oeste, a expansão da fronteira agrícola, a construção da transamazônica.

- Discussão sobre o território brasileiro a partir do conceito de espaço geográfico (do meio natural ao meio técnico-científico-informacional.

- Realização de uma pesquisa a respeito de: a) O "meio natural" no Brasil.

b) O "meio-técnico-científico-informacional" no Brasil.

- Debate acerca dos temas pesquisados, refletindo sobre a ação do homem sobre a natureza, suas consequências e possíveis, soluções para os problemas
Os educandos criaram um grupo no WhatsApp, onde compartilharam no decorrer da semana imagens, vídeos e comentários sobre os assuntos abordados em sala de aula.

Imagens que ilustrem o Brasil do meio natural e do meio técnico e técnico-científico-informacional.

Postagem no facebook da imagem, com uma breve explicação do tema. 
DOI: $10.12957 /$ teias.2021.59996

\begin{tabular}{|c|c|c|}
\hline & ambientais. & \\
\hline $\begin{array}{l}\text { Transformações no } \\
\text { espaço brasileiro }\end{array}$ & $\begin{array}{l}\text { - Reflexão acerca das transformações do espaço brasileiro. } \\
\text { - Dialogo sobre a concentrada de indústrias no Sudeste e Sul do Brasil. } \\
\text { - Relação entre industrialização e urbanização e problemas ambientais. }\end{array}$ & $\begin{array}{l}\text { Charges postadas no facebook do } \\
\text { colégio a respeito do modo de vida } \\
\text { (consumo e descarte de resíduos } \\
\text { sólidos e efluentes). }\end{array}$ \\
\hline $\begin{array}{l}\text { Regionalização do } \\
\text { espaço brasileiro }\end{array}$ & $\begin{array}{l}\text { - Caracterização física, política e econômica da regionalização brasileira, a } \\
\text { partir Atlas Geográfico Escolar. } \\
\text { - Identificação de problemas ambientais emergentes no Brasil. }\end{array}$ & $\begin{array}{l}\text { Pesquisa sobre as características das } \\
\text { regiões geoeconômicas, física e } \\
\text { política. } \\
\text { Slides postados no Facebook e no } \\
\text { grupo do Whats App. }\end{array}$ \\
\hline Amazônia & $\begin{array}{l}\text { - Diálogo promovido a partir da visualização e reflexão do documentário } \\
\text { Sociedade Anônima (Disponível em: https://youtu.be/b9Tko_q_QGM) e do } \\
\text { texto "Propostas para proteção ecológica e desenvolvimento socioambiental da } \\
\text { Amazônia" de autoria de Ab’Saber (1999). }\end{array}$ & $\begin{array}{l}\text { Postagem breve de um comentário } \\
\text { síntese do dialogo promovido em } \\
\text { sala de aula no Facebook e/ou } \\
\text { Whats App. }\end{array}$ \\
\hline Povos da Amazônia & $\begin{array}{l}\text { - Discussão sobre os usos naturais e conflitos existentes na Amazônia, a partir } \\
\text { de mapas sobre as terras indígenas e dos quilombolas e do texto "Movimentos } \\
\text { sociais e desenvolvimento sustentável" contido no livro didático (Martins, } \\
\text { Bigotto, Vitiello, 2015) } \\
\text { - Exploração do vídeo "Momento ambiental: Quebradeiras de Coco" } \\
\text { (Disponível em: https://youtu.be/SlTt-MN7nhE). } \\
\text { - Reflexão sobre os temas propostos para elaboração do cartaz, a saber: } \\
\text { Projetos de desenvolvimento sustentável na Amazônia; comunidades de } \\
\text { quilombolas da Amazônia; os seringueiros; povos indígenas remanescentes; } \\
\text { quebradeiras de coco de babaçu; pescadores e ribeirinhos. }\end{array}$ & $\begin{array}{l}\text { Cartaz realizado em grupo e } \\
\text { exposto no colégio. }\end{array}$ \\
\hline
\end{tabular}

Fonte: elaboração dos autores, 2021.

As postagens tiveram a função de conduzir o educando a refletir, tomar uma postura ativa, dar sua opinião e conscientizar-se da necessidade de tomar novas atitudes rumo a uma sociedade mais justa e sustentável.

Ao criarem seus próprios posts, a partir do que foi debatido nas aulas, os educandos demonstraram conhecimento dos temas.

A análise dos resultados da prática deu-se para além dos conteúdos trabalhados, uma vez que os conteúdos foram considerados como estruturantes e promovedores das problematizações, visando uma Educação Ambiental Libertadora.

\section{A PRÁTICA DA “TRÍADE DA CONSCIENTIZAÇÃO”: UMA ANÁLISE}

Partindo da concepção de que conscientização é explicitamente assumida como finalidade da educação, por provocar uma atitude crítica e de reflexão que compromete a ação, a estratégia metodológica proposta promoveu a criticidade e a curiosidade epistemológica, potencializando a criatividade da ação transformadora (FREITAS, 2001) dos educandos, como sujeitos históricos e sociais (FREIRE, 1997).

$\mathrm{Na}$ interação educando-educador e educando-educando, o saber é criado e recriado, o oposto do modelo tradicional, em que o saber é transmitido, muitas vezes sem um significado para o educando.

Assim, a Tríade da Conscientização conduz o educando a refletir como tem se dado a relação do ser humano com o meio ambiente por meio das atividades desenvolvidas. $\mathrm{Na}$ perspectiva de que os problemas ambientais estão intimamente ligados aos problemas sociais e que a crise ambiental não expressa os problemas da natureza, mas problemas que se manifestavam na natureza. Uma Educação que luta por uma nova sociedade capaz de viver harmonicamente com o meio ambiente (LOUREIRO e LAYRARGUES, 2013; SAUVÉ, 2016). 
A relação ser humano/meio ambiente "tem caráter indicotomizável: ser humano e natureza estão em permanente processo dialético" (DICKMANN, 2015, p. 41).

Para tanto, é latente a necessidade de uma conscientização das causas e efeitos das ações humanos no meio ambiente. A ação deve "superar a falsa consciência" (FREIRE, 1977, p.105). A ação é o fazer e o saber reflexivo. O saber que realimenta criticamente o fazer, uma unidade dialética de ação-reflexão FREIRE, 1984).

Entende-se que a conscientização é ponto de partida para uma Educação Libertária e transformadora da realidade. A educação é dialógico-dialética, por isso, os educandos precisam partir do que são para o que querem ser (FREIRE, 1978).

A Figura 2, expõe as categorias adotadas nesta pesquisa com base na Teoria Freiriana.

Figura 2: Dialética de ação-reflexão Freiriana.

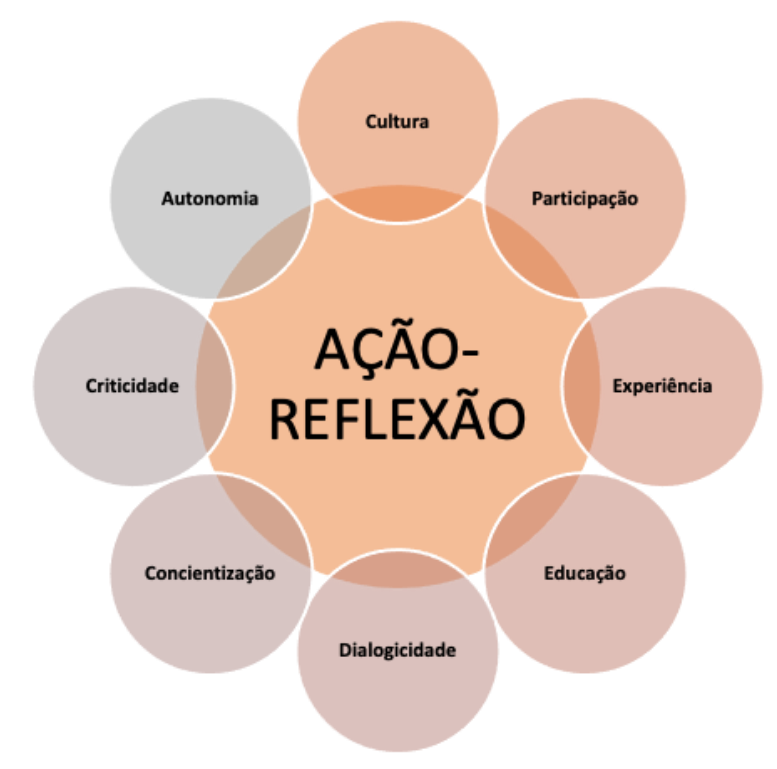

Fonte: Os autores 2021.

Durante a aplicação da metodologia, por meio dos temas abordados na Geografia, ocorreu a valorização do conhecimento prévio, a participação e o interesse dos educandos. Temas como epidemia (Dengue, Zika e Chikungunya) e corrupção emergiram no diálogo, à medida que os educandos estabeleceram relações entre os problemas locais.

$\mathrm{Na}$ tabela 3, tem-se os principais temas de Educação Ambiental que emergiram durante a prática da metodologia. Tais temas compreenderam cinco dimensões para atuação sustentável no planeta (PNUD, 2916), de acordo com a Agenda 2030 de desenvolvimento da ONU: a dimensão econômica (injustiça, desigualdade - pobreza), a dimensão social (injustiça, consumismo, individualismo, corrupção, ética, política, violência), a dimensão ecológica (epidemias, desmatamento, destino de resíduos e efluentes, poluição), a dimensão holística (crise civilizatória) e espacial (injustiça, desigualdade, pobreza, consumismo). 
DOI: $10.12957 /$ teias.2021.59996

Figura 3: Temas emergentes de Educação Ambiental

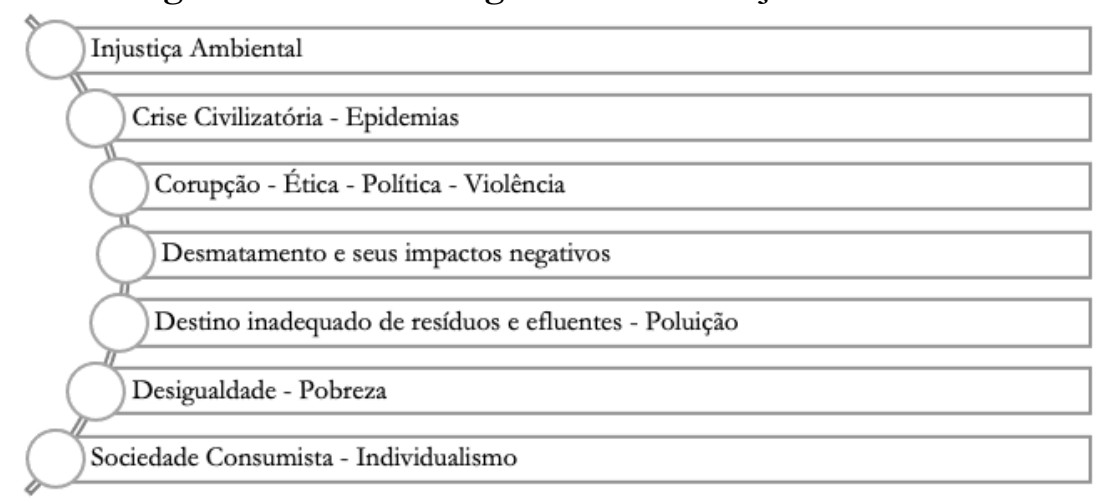

Fonte: Os autores, 2021.

Um dos temas recorrentes foi a corrupção. Esse tema emergiu devido ao contexto histórico vivenciado pelos educandos no ano de 2016, período em que havia uma discussão a respeito de impeachment da presidenta da república e de operações de combate a corrupção. As duas falas a seguir, exemplificam pensionamentos a favor e contra o impeachment da presidenta Dilma:

- "Tem que fazer impeachment sim, porque a Dilma quebrou o país". (João)

- "Se não fosse o PT, tinha gente que não tinha o que comer em casa". (Pedro)

É possível notar que ambas as falas estão condizentes com clima político na qual o país passava, noticiados na mídia impressa e televisiva. Deixando de lado os pré-conceitos expostos nas falas supracitadas, enquanto educadores, buscou-se incentivar a voz e o posicionamento dos educandos diante dos fatos ocorridos. Freire (1994), defende a necessidade de respeitar o saber do educando e ouvir a sua voz para que educador e educando produzam um saber pautado nesta interação.

É preciso quebrar certos pré-conceitos e levá-los a compreender que a mídia de massa defende seus próprios interesses. Logo, o que se torna ou deixa de tornar notícia, assim como a maneira como esta é dada, é pensada de forma que o telespectador seja conduzido a enxergar o mundo do jeito que mais interessa às corporações e sujeitos por traz destas mídias. Os educandos foram instigados a compreender que a aula não tinha o objetivo de defender ou atacar este ou aquele político, mas entender que quando há corrupção, os mais prejudicados são as pessoas menos favorecidas economicamente, os mais pobres e que, consequentemente, o meio ambiente também é afetado.

Uma conscientização sobre o modo que a sociedade urbana, capitalista, imediatista e tecnológica se relaciona com o meio ambiente, aponta para um bem-estar individual em detrimento do bem comum. Aponta ainda para o imediatismo em detrimento do planejamento e da prudência e, enfim, para uma acumulação de riquezas em detrimento de compartilhar e usufruir com parcimônia. É preciso redefinir esta consciência individualista, ou seja, ter uma nova postura apesar da cultura consumista posta. Sendo assim, a educação neste contexto passa a ter a função de promover a superação da falsa consciência que oprime e manipula.

O conceito da instalação de uma crise civilizatória, em resposta as formas de ocupação do espaço e apropriação da natureza se fizeram presente nas aulas, mas com maior intensidade nos 
posts criados pelos educandos e postados nas redes sociais. Entendida como a "degradação ambiental (...) marcada pelo modelo de modernidade regido pelo predomínio do desenvolvimento da razão tecnológica sobre a organização da natureza" (LEFF, 2001, p. 17).

A injustiça ambiental "caracteriza-se quando na sociedade se destina a maior carga dos danos ambientais a grupos sociais de trabalhadores ou grupos étnicos discriminados, entre outros segmentos em estado de maior vulnerabilidade social e econômica" (LOUREIRO e LAYRARGUES, 2013, p. 63).

Os educandos entendem que a falta de recursos financeiros contribui para a injustiça ambiental, mas ainda não estão prontos para questionar a distribuição de renda, bem como essa situação tem se perpetuado em nosso país desde a colonização, pois, de modo geral, a classe menos favorecida é formada por descendentes de escravos e indígenas.

A internalização do conceito de injustiça ambiental ficou evidenciada em respostas a questionamentos, a exemplo da questão: "Você acha que os problemas ambientais são agravados pelo baixo rendimento das famílias?", a saber:

- "Sim, quanto mais baixo o rendimento, em um lugar mais precário ele vai morar". (Maria)

- "Não, são agravados pela péssima administração do governo". (José)

A pobreza como consequência de sofrimento e causa dos problemas socioambientais, também foi apontada por outros educandos. A pobreza leva a uma segregação socioespacial, onde pessoas com menor poder aquisitivo são levadas a ocuparem espaços periféricos e com maior risco a desastre, como planícies de inundação, áreas ribeirinhas e encontras declivosas. Ou seja, tais pessoas estão mais vulneráveis a eventos adversos, a sofrerem danos (VESTENA, 2017). Apesar de pobreza não ser sinônimo de vulnerabilidade, elas "são condições sociais que se reforçam mutuamente" (VESTENA, 2017, p. 91). No entanto, educandos apontam a responsabilidade é do governo.

Apesar de não haver questionamento do porquê da pobreza, os educandos entendem que a falta de recursos financeiros contribui para a injustiça ambiental, mas não questionam a distribuição de renda. Tal como a má distribuição e concentração de renda se perpetua em nosso país desde a colonização. A classe menos favorecida brasileira é formada ainda em maior proporção pelos descendentes de escravos e indígenas, enquanto que a elite dominante mantém seu poder, detendo os meios de produção.

Ao serem questionados se é possível estabelecer uma relação entre o grau de alfabetização, os rendimentos e os problemas socioambientais, os educandos afirmaram que: " $A s$ populações que tem menos estudo, tem uma renda menor, por isso vivem em lugares onde tem desmoronamentos, dengue e problemas com esgoto". (Fernanda)

Outros educandos chegaram a conclusões semelhantes do exposto acima, ao constatarem que a injustiça ambiental está associada a baixa renda e baixa escolaridade, sendo que, uma alimenta a outra e todas alimentam uma sociedade de injustiça, desigualdade e problemas ambientais. Porém, não ressaltaram a falta de escolaridade que na maioria das vezes, não é uma opção, mas um obstáculo quase instransponível na vida dos mais pobres.

O uso dos recursos didáticos tecnológicos na metodologia proposta e desenvolvida possibilitou ao educando transpor barreiras culturais, observar e compreender os processos ambientais e diferentes realidades até então não familiares. 
Freire (2003), fala da importância da escola se reinventar, aceitar mudar em função da existência crescente de outros instrumentos. Não se trata do fim da escola, mas de uma revolução.

O uso da internet para pesquisa e o smatphone se tornam ferramentas de aprendizado em sala de aula e fora dela também, uma vez que possibilita estabelecer uma relação permanente de ensino e aprendizagem, entre educandos e educados, como proposto em Moran (2013). Também agregou abordagens dinâmicas e amplas que transpuseram os limites da sala de aula como pensado e incentivado por Romanó (2009), ao se fazer uso das redes sociais.

Para Moran (2013), o grande desafio do educador é tornar a informação significativa, escolher aquelas que realmente são importantes entre todas as possibilidades, compreendê-las de forma abrangente e torná-las parte de seu referencial.

Outro tema abordado foi as consequências da urbanização sem planejamento e do descarte inadequado de resíduos sólidos, em ruas e terrenos baldios, que pode potencializar entupimento de bueiros e os alagamentos.

Em resposta a Educação Ambiental por meio da Tríade, os educandos compartilharam charges e teceram comentários sobre situações de desrespeito ao meio ambiente e consequências trágicas ao ser humano como, o rompimento de barragens em Minas Gerais, resíduos sólidos lançados em locais impróprios, dentre outros.

$\mathrm{Na}$ Tríade da Conscientização, a disciplina de Geografia, assim como proposto em Sansolo e Cavalheiro (2003), teve o papel de contribuir com a politização do educando em sala de aula e também da sociedade por meio das redes sociais, onde educandos e sociedade foram conduzidos a perceber que as ações humanas, no que dizem respeito à produção, consumo e descarte já excederam o limite suportável do meio ambiente, como afirma Guimarães (1995).

Tal metodologia levou os educandos a perceberem a necessidade de tomarem novas atitudes rumo a uma sociedade mais justa e sustentável (SAUVÉ, 2016), de maneira a buscar a sustentabilidade, onde o objetivo principal é a redução dos impactos causados pelo ser humano ao meio ambiente (LEFF, 1999).

Deu-se, ênfase as questões éticas e políticas (BRÜGGER, 1999), possibilitando aos educandos desmascararem situações de injustiça ambiental, como exposto por Loureiro e Layrargues (2013). As formas como têm se dado as relações entre ser humano/meio ambiente são nocivas, uma vez que as sociedades capitalistas ocidentais vivem, produzem e descartam sem levar em consideração o meio ambiente (MENDONÇA, 2004; VESTENA, 2003).

A prática de tomar decisões foi possibilitada aos educandos, a fim de defender uma ética que conduza a melhoria da qualidade de vida (SATO, 2002) e uma visão desmitologizada da realidade, de forma a superar a falsa consciência rumo à conscientização (FREIRE, 1977).

As redes sociais permitiram "aprender e fazer Geografia", a partir da realidade vivida pelo educando (SANTOS, 2010), garante um processo de aprendizagem permanente (MORAN, 2013) e torna a Geografia, uma disciplina complexa por princípio (MORIN, 2009).

A Tríade da Conscientização ainda tornou os conteúdos de Geografia e a Educação Ambiental acessível, interessante e significativa, além de, proporcionar ao educando prazer em aprender, - condição indispensável para que se efetive a aprendizagem (MORAN, 2013; MORAN, 2007). Ainda agregou abordagens dinâmicas e amplas que transpuseram os limites da sala de aula (ROMANÓ, 2009). 


\section{CONSIDERAÇÕES FINAIS}

A metodologia da Tríade da Conscientização mostrou-se ser eficiente na prática da Educação Ambiental, à medida que promoveu uma aprendizagem espacial, para a tomada de atitude. Os conteúdos de Geografia, que a princípio seriam ponto de partida para a Educação Ambiental numa perspectiva espacial, ao serem abordados nos moldes da "Tríade da Conscientização", tornaram-se parte da Educação Ambiental e alimentados pelos recursos didáticos tecnológicos. Isto despertou o interesse dos educandos e permitiu a estes acessar informações mais recentes que estavam além das trazidas no livro didático, bem como possibilitou que a aula continuasse para além dos muros da escola, com o uso das redes sociais.

No sentido de avaliar a aplicabilidade da metodologia, em relação ao referencial teórico consultado, pode-se destacar que a mesma conseguiu dar conta de uma Educação Ambiental contínua prevista na Lei 9.795/1999, Artigo 2, por meio dos conteúdos de Geografia, numa perspectiva espacial, visto que conscientizou os educandos quanto a conceitos da Educação Ambiental (BRASIL, 1999).

A metodologia, pautou-se nos pressupostos teóricos de Freire (1994) a medida que adotou-se uma pedagogia que inspira práticas inovadoras na luta pela emancipação. Sendo assim, como para Freire (1994), a "Tríade da Conscientização" trabalhou com os pressupostos de que não existe saber completo e que estes precisam ser reconstruídos constantemente, conduzindo o educando a uma consciência crítica.

Diante das tecnologias e dos inúmeros desafios que surgem no cotidiano escolar, o papel do educador vai além de proporcionar uma ambiência favorável ou de tornar a informação (conteúdo) significativa. O educador deve se dispor a ir além e embrenhar-se num eterno aprender, fazer e refazer-se diariamente, não se deixar vencer pelo cansaço, falta de recursos e incentivos, muito menos por não dominar as novas tecnologias que o cercam e podem lhe ser de grande utilidade.

Em contrapartida, a Tríade conseguiu contornar o sucateamento e a falta de recursos tecnológicos disponíveis na escola pública, comprovando sua aplicabilidade junto a outras turmas do Ensino Fundamental e Médio.

A aplicação da Tríade ainda evidenciou a necessidade latente de substituir os recursos didáticos tecnológicos obsoletos por recursos mais modernos, além da necessidade de investir na capacitação dos educadores, a fim de que estes possam tirar o melhor proveito dos recursos didáticos tecnológicos e melhorar, assim, a qualidade da educação pública.

Propõe-se a aplicação e validação dessa metodologia com educandos do Ensino Fundamental, ou seja, faixa etária diferenciada da comtemplada neste trabalho e em escolas com contextos sociais diversos.

\section{REFERÊNCIAS}

AB’SABER, Aziz Nacib. Amazônia: do discurso à práxis. São Paulo: Edusp, 1999.

BRASIL. Lei no 9.394/1996. Estabelece as Diretrizes e Bases da Educação Nacional. DOU 23.12.1996. 
DOI: $10.12957 /$ teias.2021.59996

BRASIL. Ministério de Educação e do Desporto. Lei no. 9.795 de 27 de abril de 1999. Dispõe sobre a educação ambiental, institui a política Nacional de Educação Ambiental e dá outras providências. Diário Oficial da República Federativa do Brasil, Brasília, n.79, 28 abr.1999.

BRASIL. Ministério de Educação e do Desporto. Diretrižes Curriculares Nacionais da educação básica. 2013.

BRÜGGER, Paula. Educaşão on Adestramento Ambiental? 2 ed. Revista e ampliada. Letras contemporâneas, 1999.

CZAPSKI, Silvia. A Implantação da Educação Ambiental no Brasil. Publicação de responsabilidade da Coordenação de Educação Ambiental do Ministério da Educação e do Desporto, Brasília - DF, 1998.

DICKMANN, Ivo. Formação de educadores ambientais: contribuições de Paulo Freire. 2015. 210f. Tese (Doutorado em Educação) - Setor de Educação, Universidade Federal do Paraná, Curitiba, 2015. FREIRE, Paulo. A Mensagem de Paulo Freire: Teoria Prática da libertação. Porto Nova Crítica, 1977.

FREIRE, Paulo. A alfabetização de adultos: é ela um quefazer neutro? Educação \& Sociedade, São Paulo, v.1, n.1, p. 64-70, 1978.

FREIRE, Paulo. Pedagogia: diálogo e conflito. São Paulo: Cortez, 1985.

FREIRE, Paulo; SHOR, Ira. Medo e ousadia: o cotidiano do professor. Rio de Janeiro: Paz e Terra, 1987.

FREIRE, Paulo. Pedagogia da Esperança. São Paulo: Paz e Terra, 1994.

FREIRE, Paulo. Pedagogia da Autonomia. Saberes necessários à prática educativa. 35 ed. São Paulo: Paz e Terra, 1996.

FREIRE, Paulo; GUIMARÃES, Sérgio. Sobre educaşão (Diálogos). 3 ed. Paz e Terra: São Paulo, 2003.

FREITAS, A.L. Pedagogia da conscientização: um legado de Paulo Freire à formação de professores. Porto Alegre: Edipucrs, 2001.

GOMES, Jéssica Aline Cardoso; MENDES, Carla Cristina Moura; SILVA, Gerciane Martins da; FONTES, Lúcia Silva; VELOSO, Caio. Educação Ambiental: concepções e práticas docentes. In: VIANA, Victória do Nascimento; OLIVEIRA, Wellington Romão Oliveira; MACIEL, Aline Neris de Carvalho; SILVA, Edson Vicente da (orgs.). Educação ambiental formal e informal. Tomo IV. Mossoró: Edições UERN, 2017. p. 108-115.

GUIMARÃES, Mauro. A dimensão ambiental na educação. Campinas: Papirus, 1995.

KRONBAUER, Luiz Gilberto. Ação-reflexão. In: STRECK, Danilo Romeu; REDIN, Euclides; ZITKOSKI, Jaime José. Dicionário Paulo Freire. Belo Horizonte. Autêntica, 2008. p. 27-29.

LEFF, Enrique. Educação Ambiental e desenvolvimento sustentável. In: REIGOTA, Marcos (org.). Verde cotidiano: O meio ambiente em discussão. Rio de Janeiro: DP\&A, 1999.

LEFF, Enrique. Saber ambiental: Sustentabilidade, racionalidade, complexidade, poder. Tradução de Lucia Mathilde Endlich Orth. Petrópolis, RJ: Vozes, 2001. 
LOUREIRO, Carlos Frederico Bernardo; LAYRARGUES, Philippe Pomier. Ecologia Política, Justiça e Educação Ambiental Crítica: perspectivas de aliança contra-hegemônica. Trab. Educ. Saúde, Rio de Janeiro, v.11, n.1, p.53-71, 2013.

MARQUES, Silvia Patrícia da Silva. Tríade da conscientização: uma metodologia de educaşão ambiental pautada no ensino de geografia, facilitada pelo uso dos recursos didáticos tecnológicos. 2016. 182f. Dissertação (Mestrado em Geografia) - Universidade Estadual do Centro-Oeste, Guarapuava, 2016.

MARQUES, Silvia Patrícia da Silva; VESTENA, Carla Luciane Blum. Tríade da sensibilização ambiental: o uso das novas tecnologias aliada à prática de Educação Ambiental e o ensino na geografia, RevBEA, Brasília, v.11, n.4, p.336-349, 2016.

MARTIN, Dadá; BIGOTTO, Francisco; VITIELLO, Márcio. Geografia Sociedade e Cotidiano: espaço brasileiro. 3 Ed. São Paulo: Escala Educacional, 2015.

MARX, Karl.; ENGELS, Friedrich. A ideologia alemã. São Paulo: Cortez/Moraes, 1984.

MENDONÇA, Francisco. Geografia e meio ambiente. 7 Ed. São Paulo: Contexto, 2004.

MORAN, José Manuel. A TV digital e a integração das tecnologias na educação. Texto publicado no boletim 23 sobre Mídias Digitais do Programa Salto para o Futuro. TV Escola - SEED, novembro, 2007.

MORAN, José Manuel; MASETTO, Marcos Tarciso; BEHRENS, Marilda Aparecida. Novas tecnologias e mediação pedagógica. Campinas, São Paulo: Papirus, 2013.

MORIN, Edgar. A cabeça bem feita: repensar a reforma, reformar o pensamento. Trad. Jacobina. 16 ed. Rio de Janeiro: Bertrand Brasil, 2009.

ROMANÓ, Rosana Schwansee. Ambientes virtuais para a aprendizagem colaborativa no ensino fundamental. 2002. 102p. Dissertação (Mestrado em Engenharia de Produção) - Universidade Federal de Santa Catarina, Florianópolis, 2002.

PNUD. Os Objetivos de Desenvolvimento do Milênio. 2016. Disponível em: <http://www.pnud.org.br/odm.aspx>. Acesso em: 20 mai. 2016.

SANSOLO, Davis Gruber; CAVALHEIRO, Felisberto. Geografia e educação ambiental. In: SANTOS, José Eduardo; SATO, Michèle. A Contribuição da Educaşão Ambiental à Esperança de Pandora. 2 ed. São Carlos: RiMa, 2001, 2003, p. 109-131.

SANTOS, Rosane Maria Rudnick dos; SOUZA, Sandra Mara Lopes de. O ensino de geografia e suas linguagens. (Coleção Metodologia do Ensino de História e Geografia; v. 8). Curitiba: Ibpex, 2010.

SATO, Michèle. Educação Ambiental. São Carlos: Programa Integrado de Pesquisa, PPG-ERN, UFSCar, 1994.

SATO, Michèle. Educação Ambiental. São Carlos: Rima, 2002.

SAUVÉ, Lucie. Viver juntos em nossa terra: desafios contemporâneos da educação ambiental. Revista Contrapontos, Itajaí, v. 16, n. 2, 2016.

VESTENA, Carla Luciane Blum. Sensibilização ambiental: um diagnóstico na bacia hidrográfica do Rio Belém, Curitiba-PR, a partir da percepção de alunos do ensino fundamental. 2003. 164f. Dissertação (Mestrado em Geografia) - Universidade Federal do Paraná, Curitiba, 2003.

VESTENA, Carla Luciane Blum. Piaget e a questão ambiental: Sujeito epistêmico, diagnóstico e considerações educacionais. São Paulo, SP: Cultura acadêmica, 2011. 
VESTENA, Carla Luciane Blum; VESTENA, Leandro Redin. Análise da percepção e das práticas de Educação Ambiental em escolas de Curitiba/PR: subsídio à sensibilização socioambiental. Ateliê Geográfico, São Paulo, v.11, n.1, p.87-108, 2017.

VESTENA, Leandro Redin. Desnaturalização dos desastres: em busca de comunidades resilientes. Curitiba: CRV, 2016.

\section{Informações do(a)(s) autor(a)(es)}

Silvia Patrícia da Silva Marques Correio

Secretaria Estadual de Educação do Paraná

E-mail: prof.silviapaty@gmail.com

ORCID: https://orcid.org/0000-0002-5325-355X

Link Lattes: http://lattes.cnpq.br/3113738180517240

Carla Luciane Blum Vestena

Universidade Estadual do Centro Oeste (UNICENTRO)

E-mail: cvestena@unicentro.br

ORCID: https://orcid.org/0000-0002-8655-7840

Link Lattes: http://lattes.cnpq.br/0863582713179217

Leandro Redin Vestena Correio

Universidade Estadual do Centro-Oeste (UNICENTRO)

E-mail:1vestena@unicentro.br

ORCID: https://orcid.org/0000-0002-6210-3094

Link Lattes: http:// lattes.cnpq.br/2389916164041767 